This item was submitted to Loughborough's Research Repository by the author.

Items in Figshare are protected by copyright, with all rights reserved, unless otherwise indicated.

\title{
Optimization of partially textured parallel thrust bearings with square-shaped micro-dimples
}

\section{PLEASE CITE THE PUBLISHED VERSION}

http://dx.doi.org/10.1080/10402000701429261

\section{PUBLISHER}

(C) Taylor \& Francis

\section{VERSION}

AM (Accepted Manuscript)

\section{PUBLISHER STATEMENT}

This work is made available according to the conditions of the Creative Commons Attribution-NonCommercialNoDerivatives 4.0 International (CC BY-NC-ND 4.0) licence. Full details of this licence are available at: https://creativecommons.org/licenses/by-nc-nd/4.0/

\section{LICENCE}

CC BY-NC-ND 4.0

\section{REPOSITORY RECORD}

Rahmani, Ramin, Ayoub Shirvani, and Hassan Shirvani. 2019. "Optimization of Partially Textured Parallel Thrust Bearings with Square-shaped Micro-dimples”. figshare. https://hdl.handle.net/2134/15884. 
Tribology Transactions, 2007, Vol. 50, No. 3, pp. 401-406

(Accepted Version)

\title{
OPTIMIZATION OF PARTIALLY TEXTURED PARALLEL THRUST BEARINGS WITH SQUARE- SHAPED MICRO-DIMPLES
}

\author{
Ramin Rahmani, Ayoub Shirvani, Hassan Shirvani \\ Faculty of Science and Technology, Anglia Ruskin University \\ Victoria Road South, Chelmsford, CM1 1LL, UK \\ Phone: +44 (1245) 493131 ext. 3395; Fax: +44 (1245) 493136 \\ Email: r.rahmani@apu.ac.uk
}

\begin{abstract}
In this study we attempt to find the optimum geometrical parameters of square-shape micro-dimples imposed on parallel flat bearing surfaces which give the best tribological performance, including load capacity and friction coefficient. An analytical solution of Reynolds equation for the surfaces involving numerous dimples is presented, then considering the variations of number of dimples as well as dimple length and height ratios for a constant dimpled length, it is tended to get the optimum value of parameters. It is shown that despite the variations of different studied geometrical parameters, it seems the optimum value of these parameters remain nearly constant.
\end{abstract}

Keywords: surface texturing; optimization; load capacity; friction coefficient

\section{NOMENCLATURE}

$c_{1} \quad$ integration constant

$c_{2} \quad$ integration constant

$d \quad$ distance between dimples [m]

$D \quad$ length of dimpled section [m]

$F \quad$ friction force [N]

$h \quad$ bearing surface profile [m]

$H \quad$ minimum film thickness [m]
$H_{D} \quad$ dimple height $[\mathrm{m}]$

$i \quad$ summation index

$j \quad$ summation index

$L \quad$ bearing length [m]

$l_{D} \quad$ dimple length $[\mathrm{m}]$

$l_{0} \quad$ starting length $[\mathrm{m}]$

$l_{n} \quad$ ending length [m]

$m$ number of dimples

$p \quad$ pressure $[\mathrm{N} / \mathrm{m}]$

$P_{M} \quad$ total average pressure $[\mathrm{N} / \mathrm{m}]$

$P_{x 0} \quad$ pressure at $x=x_{0}[\mathrm{~N} / \mathrm{m}]$

$P_{x n} \quad$ pressure at $x=x_{n}[\mathrm{~N} / \mathrm{m}]$

$u \quad$ velocity profile inside lubricant film $[\mathrm{m} / \mathrm{s}]$

$U$ tangential bearing surface velocity $[\mathrm{m} / \mathrm{s}]$

$W \quad$ load capacity [N]

$x \quad x$-coordinate

$y \quad y$-coordinate

\section{Greek symbols}

$\varepsilon \quad$ dimple length ratio

$\varepsilon_{0} \quad$ length ratio at starting

$\varepsilon_{n} \quad$ length ratio at ending

$\eta \quad$ friction coefficient

$\mu \quad$ lubricant dynamic viscosity [ $[\mathrm{kg} / \mathrm{m} . \mathrm{s}]$

$\tau \quad$ wall shear stress $[\mathrm{N} / \mathrm{m}]$ 
Tribology Transactions, 2007, Vol. 50, No. 3, pp. 401-406

$\xi \quad$ dimple height ratio

\begin{tabular}{|c|c|}
\hline Sub & pts \\
\hline atm & atmospheric condition \\
\hline 0 & condition at the starting section \\
\hline $\begin{array}{l}\mathrm{n} \\
\mathrm{opt}\end{array}$ & $\begin{array}{l}\text { condition at the ending section } \\
\text { optimum }\end{array}$ \\
\hline
\end{tabular}

Abbreviations

CFD computational fluid dynamics

LST laser surface textured

\section{INTRODUCTION}

Classical notes on hydrodynamic lubrication show that smooth parallel sliding surfaces under common circumstances do not have any contribution in load carrying due to pure sliding effect. However, giving even very small irregularity to one of the surfaces might result in very large load capacity to this type of bearings. Using the calculus of variations it is shown that among common bearing surface profiles for thrust bearings, the Rayleigh step bearing has the maximum load capacity [1]. On the other hand, over the last decade using controlled implanted surface irregularities especially using the Laser technology has become popular in bearing technology, since it is realized that this type of surface enhancement would give a better tribological performance. There is quite considerable experimental works on the investigation of effectiveness of this type of surfaces in increasing the load capacity or reducing the friction coefficient while the lack of analytical works is considerable too [2-5]. Furthermore, it is shown that these micro-irregularities would give a better result even in relatively extreme lubrication situations like boundary lubrication by transition of the conditions to hydrodynamic or mixed lubrication modes [4]. Finding the optimum geometry and arrangement for micro-dimples seems also to be one of the interesting research areas in this field.

Among the theoretical works, Burstein and Ingman [6] have studied the effect of pore ensemble statistics in improving the tribological characteristics of bearings under reciprocating motion. The idea behind their work is that there is no need for the perfect identification of the pores during production, but pore ensemble statistics must be taken into consideration in correct lubrication calculations. Brizmer et al. [7] have theoretically investigated the potential use of laser surface texturing technology in parallel thrust bearings. They have reported the optimum parameters of dimples and best partial laser surface textured (LST) condition in order to obtain maximum load carrying capacity. It is shown that there is an optimum for the textured portion of slider width which reduces its value by increasing of slider aspect ratio. They conclude that the micro-dimple "individual effect", which corresponds to full width texturing, is not useful for developing the large load carrying capacity expected from a hydrodynamic thrust bearing. In [8] Sahlin has investigated the hydrodynamic lubrication of textured surfaces using CFD. He simulated the circular and splined type surface irregularities in relatively high Reynolds numbers. It is concluded that the load capacity increases with increasing dimple cross sectional area and an optimum for load capacity is achievable when the height ratio lies in the range of 1.5 to 1.75 for all geometries and groove widths. Jo [9] has studied the laser textured surfaces in relatively high Reynolds numbers and has found that the textured surface performance may vary by the shape of microdimples. On the other hand, results from [10] show that the effect of dimple shape (positive and negative) is minimal on coefficient of friction. In addition, Wakuda et al. [5] have also shown experimentally that the dimple geometry has little influence on the frictional properties regardless of rounded or angular profiles. An experimental work by Kovalchenko et al. [4] reveals that a lower area dimple density is more beneficial for lubrication regime transitions. In addition, Etsion et al. in their work [11] have demonstrated that the effect of the pore's depth over diameter ratio is very significant on the average pressure, while the area density of the pores have very little effect on the average pressure.

The present work is focused to analyse the interaction of micro-square-dimples in hydrodynamic lubrication mode to find the probable optimum parameters based on either load capacity or friction force. As it is noted, most of results from the literature review show that there is a minor effect of dimple's shape on tribological characteristics of LST surfaces, therefore in the present study the square-type dimples are chosen to analyse due to their simplicity to use in analytical formulization of the problem. To get results, first it is intended to find a solution of the Reynolds equation which is suitable to impose on the cases in which there might be numerous surface irregularities like square shaped dimples. Then the results are presented for the case of parallel flat plate sliders partially dimpled with square-dimples with equal geometry. The effect of variation of three geometric parameters for dimples is studied including number of dimples, ratio of dimple's length to dimple's distance from each other, called length ratio and the ratio of dimple's height to minimum film thickness, called height ratio. In the present study it is assumed that the dimpled length is constant for all of the geometrical variations inside dimpled area. Finally, using a simple in-house search/optimization genetic algorithm code a relatively exact optimum values of height ratio for different dimple numbers as well as length ratios are computed.

\section{PROBLEM FORMULIZATION}

The one-dimensional steady Reynolds equation for an incompressible lubricant with constant viscosity can be expressed in the following form:

$$
\frac{\partial}{\partial x}\left(h^{3}(x) \frac{\partial p(x)}{\partial x}\right)=6 \mu U \frac{\partial h(x)}{\partial x}
$$

Double integrating of this equation with respect to $x$, will result in the pressure distribution along the bearing:

$$
p(x)=6 \mu U \int_{x_{0}}^{x} \frac{1}{h(s)^{2}} d s+c_{1} \int_{x_{0}}^{x} \frac{1}{h(s)^{3}} d s+c_{2}
$$

In which $c_{1}$ and $c_{2}$ are integration constants. Defining the boundary conditions for pressure as below:

$$
\left\{\begin{array}{l}
\left.p\right|_{x=x_{0}}=P_{x_{0}} \\
\left.p\right|_{x=x_{n}}=P_{x_{n}}
\end{array}\right.
$$


In which $x_{0}$ and $x_{n}$ are the coordinates of the end points of the bearing geometry (Fig. 1). Using these boundary conditions, the integration constants would be determined as follow:

$$
\left\{\begin{array}{l}
c_{1}=\frac{\left(P_{x_{n}}-P_{x_{0}}\right)-6 \mu U \int_{x_{0}}^{x_{n}} \frac{1}{h(x)^{2}} d x}{\int_{x_{0}}^{x_{n}} \frac{1}{h(x)^{3}} d x} \\
c_{2}=P_{x_{0}}
\end{array}\right.
$$

In general, the surface profile for the given geometry in Fig. 1 can be defined as:

$$
h(x)=\left\{\begin{array}{lc}
h_{1} ; & x_{0} \leq x \leq x_{1} \\
h_{2} ; & x_{1}<x \leq x_{2} \\
\mathrm{M} & \mathrm{M} \\
h_{n} ; & x_{n-1}<x \leq x_{n}
\end{array}\right.
$$

Using this surface profile, the pressure distribution for any specified portion of the bearing length can be expressed in the form of:

$$
\begin{aligned}
& \left.p(x)\right|_{x \in\left[x_{i-1}, x_{i}\right]}=6 \mu U\left[\frac{\left(x-x_{i-1}\right)}{h_{i}^{2}}+\sum_{j=1}^{i-1} \frac{\left(x_{j}-x_{j-1}\right)}{h_{j}{ }^{2}}\right] \\
& +c_{1}\left[\frac{\left(x-x_{i-1}\right)}{h_{i}^{3}}+\sum_{j=1}^{i-1} \frac{\left(x_{j}-x_{j-1}\right)}{h_{j}{ }^{3}}\right]+c_{2}
\end{aligned}
$$
as follow:

$$
c_{1}=\frac{\left(P_{x_{n}}-P_{x_{0}}\right)-6 \mu U \sum_{i=1}^{n} \frac{\left(x_{i}-x_{i-1}\right)}{h_{i}^{2}}}{\sum_{i=1}^{n} \frac{\left(x_{i}-x_{i-1}\right)}{h_{i}^{3}}}
$$

The total average pressure is:

$$
P_{M}=\frac{1}{\left(x_{n}-x_{0}\right)} \int_{x_{0}}^{x_{n}} p(x) d x
$$

Replacing pressure distribution from (6) and integrating would result in:

$$
\begin{aligned}
& P_{M}=6 \mu U \sum_{i=1}^{n}\left\{\begin{array}{l}
\frac{\left[\left(x_{i}^{2}-x_{i-1}^{2}\right)-2 x_{i-1}\left(x_{i}-x_{i-1}\right)\right]}{2 h_{i}^{2}\left(x_{n}-x_{0}\right)} \\
+\frac{\left(x_{i}-x_{i-1}\right)}{\left(x_{n}-x_{0}\right)} \sum_{j=1}^{i-1} \frac{\left(x_{j}-x_{j-1}\right)}{h_{j}^{2}}
\end{array}\right\} \\
& +c_{1} \sum_{i=1}^{n}\left\{\begin{array}{l}
\frac{\left[\left(x_{i}^{2}-x_{i-1}^{2}\right)-2 x_{i-1}\left(x_{i}-x_{i-1}\right)\right]}{2 h_{i}^{3}\left(x_{n}-x_{0}\right)} \\
+\frac{\left(x_{i}-x_{i-1}\right)}{\left(x_{n}-x_{0}\right)} \sum_{j=1}^{i-1} \frac{\left(x_{j}-x_{j-1}\right)}{h_{j}^{3}}
\end{array}\right\}+c_{2}
\end{aligned}
$$

The load carrying ability of the bearing is calculated using the total average pressure as below:

$$
W=P_{M} \cdot L
$$

In which $L$ is the lubricating length.

The velocity profile inside lubricant film is:

$$
u(x, y)=\frac{1}{2 \mu} \frac{\partial p(x)}{\partial x}\left(y^{2}-h(x) y\right)+U\left(\frac{h(x)-y}{h(x)}\right)
$$

The wall shear stress for lower surface is defined as below:

$$
\tau(x)=\left.\mu \frac{\partial u(x, y)}{\partial y}\right|_{y=0}
$$

Replacing velocity profile from (11) we have:

$$
\tau(x)=-\frac{h(x)}{2} \frac{\partial p(x)}{\partial x}-\frac{\mu U}{h(x)}
$$

In which the pressure gradient can be directly calculated from (6).

Replacing the pressure gradient would result in the lower wall shear stress for any specified portion of the dimpled surface as below:

$$
\left.\tau(x)\right|_{x \in\left[x_{i-1}, x_{i}\right]}=-\left(4 \mu U \frac{1}{h_{i}}+c_{1} \frac{1}{2 h_{i}^{2}}\right)
$$

The total friction force is:

$$
F=\int_{x_{0}}^{x_{n}} \tau(x) d x=\left.\sum_{i=1}^{n} \int_{x_{i-1}}^{x_{i}} \tau(x)\right|_{x \in\left[x_{i-1}, x_{i}\right]} d x
$$

Replacing the wall shear stress from (13) and integrating for specified integral limitations, we have:

$$
F=-\sum_{i=1}^{n}\left[4 \mu U \frac{\left(x_{i}-x_{i-1}\right)}{h_{i}}+c_{1} \frac{\left(x_{i}-x_{i-1}\right)}{2 h_{i}^{2}}\right]
$$

Finally the friction coefficient is defined as:

$$
\eta=\frac{F}{W}
$$

In which $F$ and $W$ are replaced from (16) and (10) respectively. 


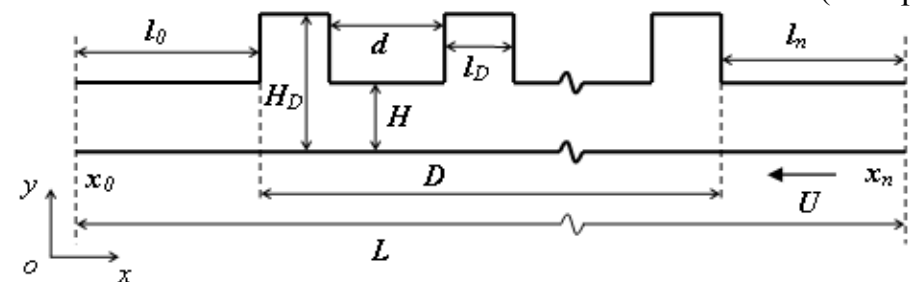

Figure 1. Studied dimple and bearing geometry

\section{RESULTS AND DISCUSSION}

To get the results it is assumed that the bearing is partially surface textured [7]. Since we have used the Sommerfeld boundary conditions, using the partially surface texturing idea enables us to locate the dimples in an area that the total produced pressure become positive for any variations in dimples geometry for the given velocity direction, although for the local pressure distribution a negative pressure may happen in some areas specially at the end part of geometry as it is shown in Fig. 1.

Two parameters are defined and used to show the geometrical variations of dimples. These parameters are the dimple height ratio and the dimple length ratio and are defined below respectively (see Fig. 1):

$$
\begin{gathered}
\xi=\frac{H_{D}}{H} \\
\varepsilon=\frac{l_{D}}{d}
\end{gathered}
$$

In addition using (19) we can define the ending length ratios as follows:

$$
\varepsilon_{0}=\frac{l_{0}}{d} \text { and } \varepsilon_{n}=\frac{l_{n}}{d}
$$

To find the optimum geometry it is assumed that the total dimpled length is constant for all cases.

In this study we confined the problem to negative dimples in which the dimple length and height ratios are in the range of $0<\varepsilon<1$ and $1<\xi<\infty$. In addition, it is assumed that the dimples have the same geometry. Referring to Fig. 1, the following parameters are fixed in all cases:

$l_{0}=2.0 \mathrm{E}-3[\mathrm{~m}] ; l_{n}=0.5 \mathrm{E}-3[\mathrm{~m}] ; H=5.0 \mathrm{E}-7[\mathrm{~m}] ; P_{x 0}=P_{x n}=P_{a t m}$; $U=-1.0[\mathrm{~m} / \mathrm{s}] ; \mu=1.06[\mathrm{~kg} / \mathrm{m} . \mathrm{s}]$.

Figure 2 shows the variations of local pressure distribution for different numbers of dimples when $\varepsilon=0.2$ and $\xi=1.8$. As it can be seen the pressure distribution at the ending part it becomes negative which in practice would lead to cavitation. Appropriate treating of the cavitation in sliding bearings can be done by applying Reynolds boundary conditions. However, since the Sommerfeld boundary condition is used here, therefore the dimpled area is chosen so that the area with negative pressure is minimized.in order to have more realistic results; whilst the real interaction of the cavitation in the results may be considered as another research topic including Reynolds boundary conditions.

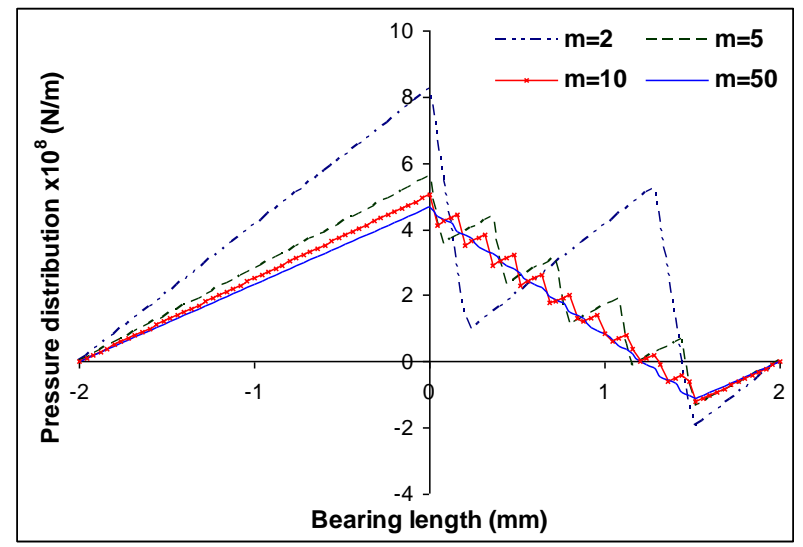

Figure 2. Local pressure distribution for different number of dimples when $\varepsilon=0.2$ and $\xi=1.8$

In general, there are three variables; potentially there might be an optimum for them regarding either load carrying ability or friction force: number of dimples and dimple's length and height ratios. Here the variations of all of these parameters would be considered.

Figure 3 shows a three dimensional view of the variations of total average pressure, friction force, and friction coefficient with number of dimples for different dimple height ratios in a constant length ratio $\varepsilon=0.05$. As can be seen increasing the number of dimples at first shows a reduction in load capacity ${ }^{1}$ as well as an increment in friction force, while increasing the number of dimples more than a specified number would make no considerable variations in either of parameters.

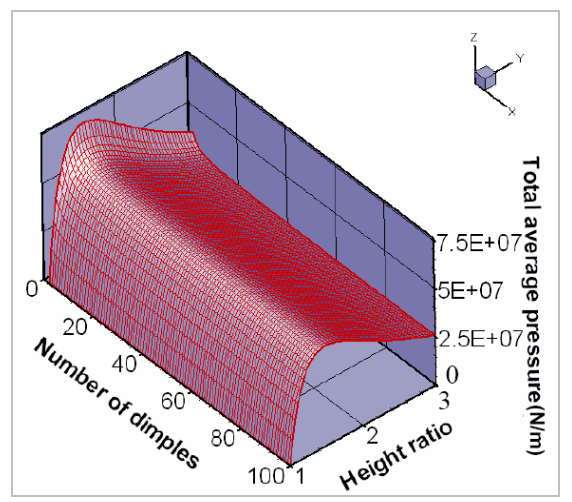

(a) Total average pressure

\footnotetext{
${ }^{1}$ Since the studied surface length is kept constant in this study, regardless of variations of either length ratio or number of dimples, therefore the trend of variations of average total pressure would be completely same as load capacity. This would allow us to use the term "load capacity" instead of "total average pressure" where we are discussing about qualitative behaviour of total average pressure.
} 
Tribology Transactions, 2007, Vol. 50, No. 3, pp. 401-406

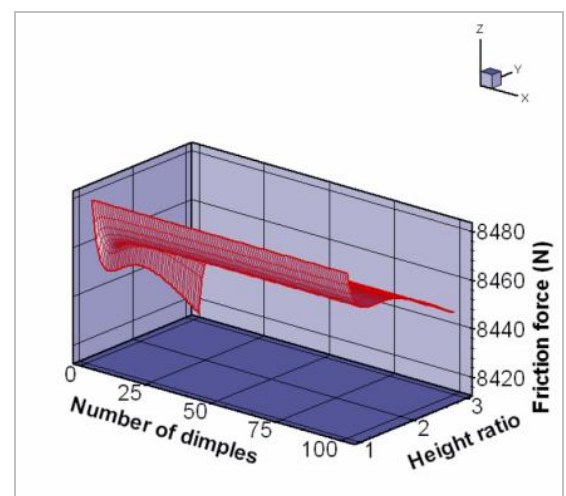

(b) Friction force

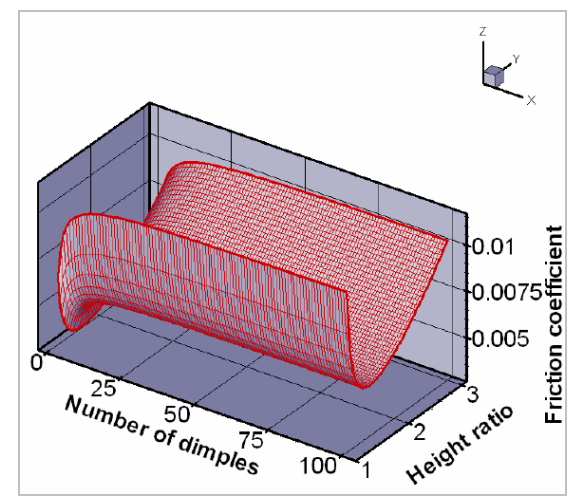

(c) Friction coefficient

Figure 3. A 3-D representation of variations of total average pressure, friction force, and friction coefficient with number of dimples for different dimple height ratios in a constant length ratio $\varepsilon=0.05$

On the other hand, if we consider the variations of height ratio, it is obvious that there is a maximum value for load capacity for each number of dimples which directly results in a minimum for friction coefficient, since for friction force it seems to be an inflection point. In contradiction to the reduction of friction force, the load capacity has a rapid growth before this optimum point for height ratio while after the optimum point, both of the load capacity and friction force are reduced. Considering the variations of friction coefficient demonstrates that for height ratios more than the optimum height ratio, the reduction of load capacity is more than of friction force. Moreover it can be observed that the optimum value for height ratio remains nearly in a constant range about 1.5 to 2 regardless of variations of number of dimples. In this case, it seems the optimum value for number of dimples is the minimum number of dimples.

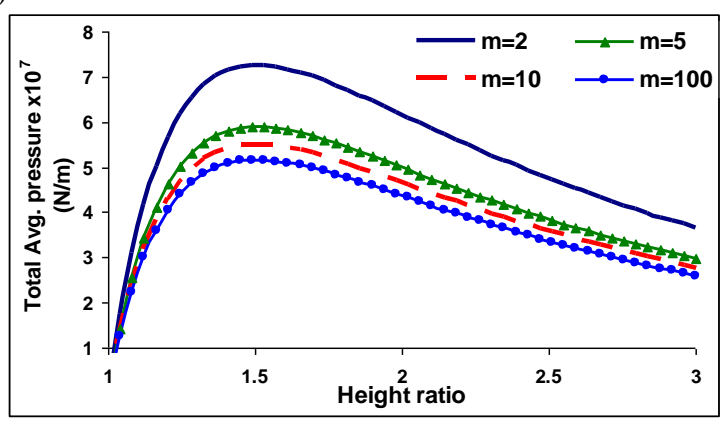

(a) Total average pressure

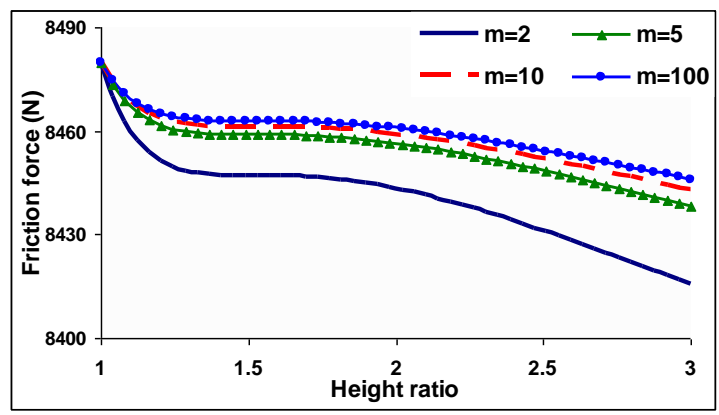

(b) Friction force

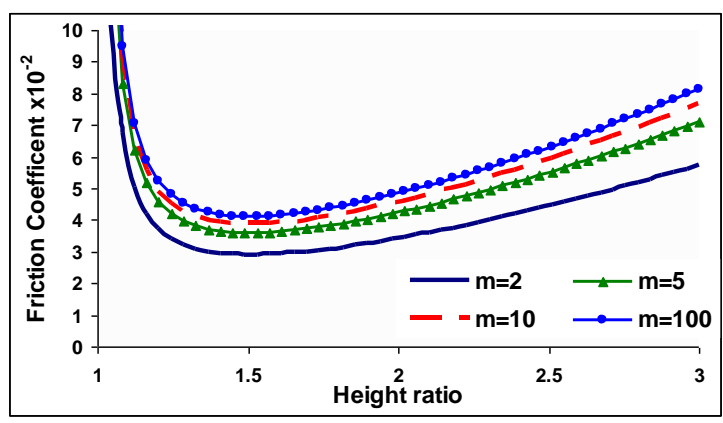

(c) Friction coefficient

Figure 4. Variations of total average pressure, friction force, and friction coefficient with number of dimples for different dimple height ratios in a constant length ratio $\varepsilon=0.05$.

Figure 4 shows a more precise view to the variations of studied parameters with height ratio for different number of dimples. As it is seen the optimum height ratio is very close to 1.5 for all number of dimples. It is therefore evident that increasing the number of dimples for partial dimpled surfaces in general would reduce the tribological performance of slider bearings. This would be expected because in the lower limiting case of reducing the number of dimples the result would be the Rayleigh step which is known as the best slider bearing geometry. 


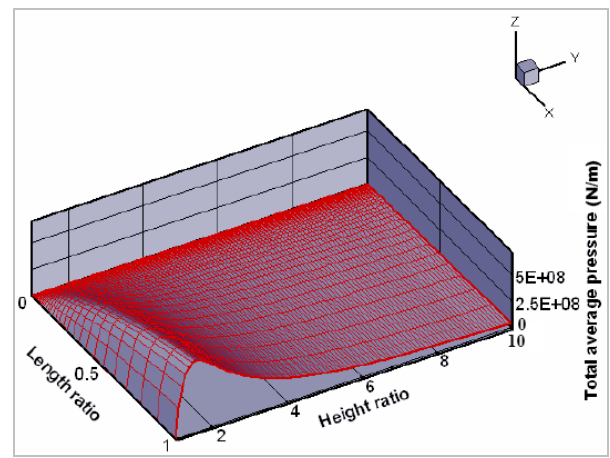

(a) Total average pressure

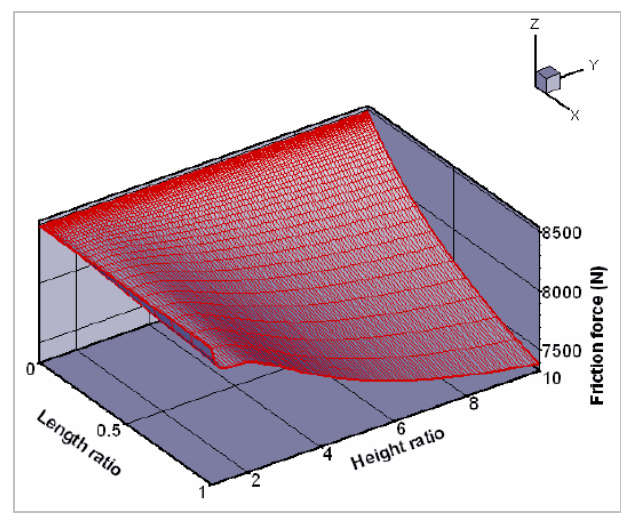

(b) Friction force

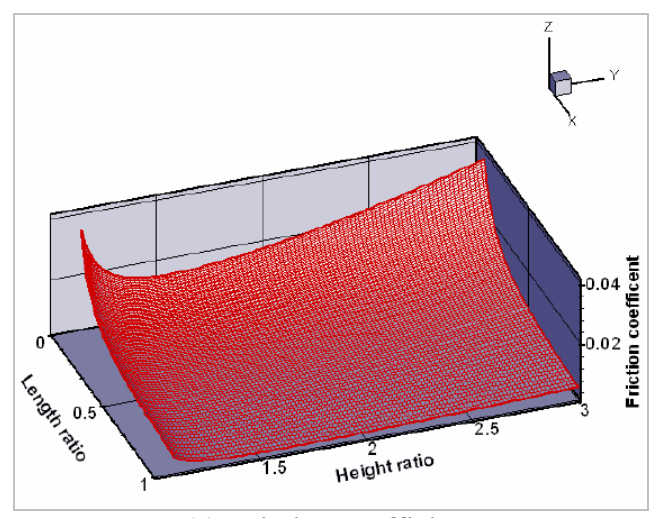

(c) Friction coefficient

Figure 5. Variations of total average pressure, friction force, and friction coefficient with dimple height ratios for different dimple length ratios in a constant number of dimples of 10 .

Figure 5 shows a three dimensional view of the variations of total average pressure, friction force, and friction coefficient with dimple height ratios for different dimple length ratios in a constant number of dimples of 10 . From the graphs in this figure it seems that in general, higher values of length ratio would give better tribological performance. In other words, the length ratio of 1 would be the optimum length ratio. As can be seen from the first graph of Fig. 4, the magnitude of optimum height ratio reduces by reducing the length ratio but it remains nearly in the same range as mentioned before.

The behaviour of the studied parameters with this optimum value of length and height ratios may allow us to call these optimum points "absolute optimums". The reason for this is that at these points both of the load capacity and friction coefficient show their optimum values. It is also of interest that these points are inflection points for friction force.

Figure 6 shows the variations of optimum dimple height ratio with dimple length ratio for different number of dimples. As it is observed, the optimum height ratio for all of the possible variations of length ratio and dimple numbers remains in the range of 1.50 to 1.57 . In conclusion, it can be stated that in the studied ranges the best performance would be achieved by dimple numbers of 2 , dimple length ratio of 1 and corresponding dimple height ratio of about 1.57 . The total average pressure and friction coefficient for this point are about $1.042 \mathrm{E}+9$ and $1.967 \mathrm{E}-3$ respectively.

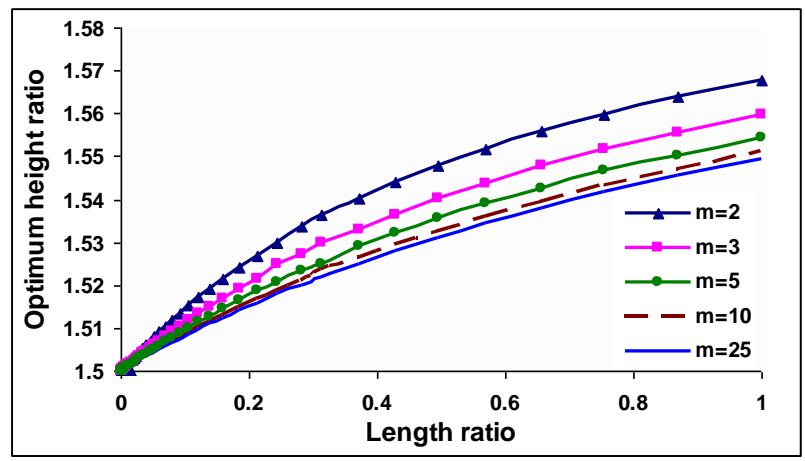

Figure 6. Optimum dimple height ratio vs. dimple length ratio for different number of dimples

\section{CONCLUSIONS}

The effect of variations of the three main geometrical parameters of square-shaped dimples on the tribological characteristics namely - load capacity, friction force and friction coefficient - of a partial surface textured parallel slider bearings has been investigated. It is shown that, for this type of surface textured bearings, it is possible to find the optimum geometry for dimples. As a direct result of this study, it can be stated that, for partial textured surfaces, increasing the number of dimples would not help in improving either of load capacity and friction coefficient in pure hydrodynamic lubrication mode. For length ratio it is shown that the best performance can be achieved by using dimples with length equal with their distance from each other, i.e. $\varepsilon_{o p t}=1$. On the other hand, it is demonstrated that the effect of variations of length ratio as well as number of dimples on the optimum height ratio is not very considerable and with a good approximation it can be expressed that a height ratio of about $\xi_{\text {opt }}=1.5$ to 1.57 would give the best performance for the studied partial textured surface. In addition, it is observed that, the optimum points for height ratio in which the resulted load capacity and friction coefficient are maximum and minimum respectively, are also an inflection point for correspondent friction force.

\section{REFERENCES}

[1] Pinkus, O., and Strenlicht, B., 1961, "Theory of hydrodynamic lubrication", McGraw-Hill Inc., US 
[2] Etsion, I., Halperin, G., Brizmer, V. and and Kligerman, Y., 2004, "Experimental investigation of laser surface textured parallel thrust bearings", Tribology Letters, 17, No. 2, pp. 295300

[3] Ryk, G, Kligeram, Y., and Etsion, I., 2002, "Experimental investigation of laser surface texturing for reciprocating automotive components", Tribology Transactions, 45, 4, pp. $444-449$

[4] Kovalchenko, A., Ajayia, O., Erdemir, A., Fenske, G., and Etsion, I., 2005, "The effect of laser surface texturing on transitions in lubrication regimes during unidirectional sliding contact”, Tribology International, 38, pp. 219-225

[5] Wakuda, M., Yamauchi, Y., Kanzaki, S., and Yasuda, Y., 2003, "Effect of surface texturing on friction reduction between ceramic and steel materials under lubricated sliding contact", Wear, 254, pp. 356-363

[6] Burstein, L., Ingman, D., 2000, "Pore Ensemble Statistics in Application to Lubrication under Reciprocating Motion", Tribology Transactions, 43, 2, 205-212
[7] Brizmer, V., Kligerman, Y., and Etsion, I., 2003, “A Laser Surface Textured parallel thrust bearing", Tribology

Transactions, 46, pp. 397-403

[8] Sahlin, F., 2003, "CFD-analysis of hydrodynamic lubrication of textured surfaces", Master's Thesis, Lulea University of Technology, Sweden.

[9] Jo, H., "Lubrication, Wear \& Bearing Technology", URL: http://www.me.utexas.edu/ bryant/courses/me383s/DownloadF iles/Sleds/Jo.pdf

[10] Siripuram, R.B., 2003, “Analysis of Hydrodynamic Effects of Microasperity Shapes on Thrust Bearing Surfaces", Master's Thesis, University of Kentucky, USA. URL: http://lib.uky.edu/ETD/ukymeen2004t00221/etd.pdf

[11] Etsion, I., Kligerman Y., and Halperin, G., 1999, "Analytical and experimental investigation of laser-textured mechanical seal faces", Tribology Transactions, 42, 3, pp. 511516 